\title{
Analysis of travel pattern and the need to develop sustainable transportation infrastructure in Sarbagita metropolitan area
}

\author{
Putu Alit Suthanaya ${ }^{1, *}$ \\ ${ }^{1}$ Civil Engineering Department, Faculty of Engineering, Udayana University, Bali-Indonesia
}

\begin{abstract}
Denpasar city is the capital of Bali Province and has been developed into a metropolitan city. There has been an agglomeration of four regencies, namely Denpasar, Badung, Gianyar and Tabanan forming a Metropolitan Sarbagita area with a population close to 2 million inhabitants. With heightened population and activity, travel patterns are increasing and scattered. The development of land use in the Sarbagita Metropolitan area occurred rapidly and was not properly anticipated by the provision of adequate infrastructure. This study aims to examine the patterns of movement that occurs and projections for future conditions as a basis to develop a more sustainable transportation infrastructure. The data used are the origin-destination of people and goods, and statistical population data. The prediction method uses four-stages modeling with the help of Visum software and was validated based on the average daily traffic (ADT) data. The results of the study indicate that traffic accumulation occurs on most arterial and collector roads especially around Denpasar with a degree of saturation exceeding 1. To anticipate future population and increased activities, developing a mass public transport system, multi-mode system, ICT system, and limiting the ownership and use of private motor vehicles is necessary.
\end{abstract}

\section{Introduction}

Many cities around the world experienced growing urban population including cities in developing countries like Indonesia [1]. Limited transport infrastructure available has caused traffic congestion problems. The population in general and road users in particular agree to less road congestion. This is especially true for emerging cities experiencing very strong increasing rates of car ownership per capita. Limited road capacity can not accomodate the exponential growth of motor vehicles. Public transport performance has decreased with a very low load factor. Urban congestion is responsible for the irregularity of bus services [2]. Travel and waiting times at bus stops are increased, and the operating costs are also increased. Despite its drawbacks, cars remain very useful tools providing incomparable freedom of movement. Although the road infrastructure may be saturated, no

\footnotetext{
* Corresponding author: suthanaya@,rocketmail.com
} 
public transport system, as developed and efficient it may be, can compete in terms of average "door-to-door" travel time with the automobile.

The travel freedoms offered by private vehicles and the low performance of public transport services has made it almost impossible to shift people from private vechilces to public transport. This requires us to rethink transportation systems as a whole, the use of existing infrastructure, and the integration of public transport and urban planning in a common model. Transportation governance and policies must be adapted in order to recover an urbanization process consistent with viable and sustainable mobility. Understanding urban travel behavior is important to solve the congestion problems.

There are many factors affecting urban travel behavior. Earlier studies have tried to investigate the travel behavior in relation to land use [3, 4, 5]. Based on study of travel behavior in Montreal, Quebec and Canada, it was found that higher income households tend to have a more dispersed travel behavior regardless of their accessibility [6]. Another study investigated the travel pattern in Nairobi, Kenya [7]. It was found that insufficient transport infrastructure has caused travel difficulty across all income groups. Low income residents tend to live in slum areas close to their employment location without being served by good pedestrian and bicycle infrastructures. Middle and high-income residents are highly dependent on using private cars which leads to congestion problems. This situation is similar to the situation in the Sarbagita metropolitan area of Bali Province. A lack of public transport, pedestrian, and bicycle facilities have caused severe traffic jams in almost all major urban roads. Another study used data in two cities, Chicago and Melbourne and analysed mobility characteristics in urban areas based on a complex network-motivated approach. They found that the travel demand network is similar although the two cities have different a topography and urban structure [8]. Travel behavior in urban areaa is also influenced by social activities. There is a correlation between the social activity and the destination choice [9]. Several studies have explored the dynamics of network traffic flows $[10,11,12]$. More recent studies have used data from GPS devices to analyse travel behavior $[13,14,15]$.

This research is devoted to understanding the serious traffic congestion faced by many cities in South-East Asian countries and the increasing need of mobility, based on a case study of the Sarbagita metropolitan area in the Province of Bali, Indonesia. The technical part is based on microscopic transport modeling urban scale of Sarbagita, from the model referred to as the four-step model (FSM) adapted to the situation and the available data. The objectives of this study are to examine the patterns of movement that occur and make a projection for future conditions as a basis for creating a more sustainable transportation infrastructure.

\section{Urban transport modelling}

Traffic flow simulation falls within more specific and short-terms approaches (improving the efficiency of a crossroads and real-time network management). It is generally affiliated to the field of traffic engineering whereas long-term transport modeling corresponds to the field of urban development. Thus, a transport model is a support tool for decision-making, centralizing all transportation data of a conurbation. It provides numerical estimates in terms of transport demand and it also provides a better identification of territory's issues by mapping it. It allows one, for example, to assess the impact of infrastructure projects, and to predict traffic volumes, service modification of public transportation, traffic flows, the modal split, and potential bottlenecks in the transport network. A transport model is generally composed of three sub-models: a demand model, a network model and different models of impact and assignment. The network model is a geographic information system (GIS) that integrates different transport systems, infrastructure and road networks as well as 
their hierarchy, capacity and traffic speeds, the description of TC lines, and the division of the territory into zones. The demand model describes the potential of attraction (jobs, commercial space, etc.) and emission of the population by area. Using indicators of supply, it allows one to calculate the associated demand for travel mode. The allocation model calculates routes for each trip.

This step corresponds to the trip generation of the four-step model. The process aims to estimate productions and attractions for each trip purpose of each zone, separately from the others. Here is the classic formula for productions and attractions [16]:

$$
\begin{aligned}
& P_{i}^{p}=f_{P}^{p} \text { (A activity system characteristics) } \\
& A_{j}^{p}=f_{A}^{p} \text { (A activity system characteristics) }
\end{aligned}
$$

$P$ or $A$ for production or attraction, $p$ for trip purpose, function of the activity system.

The next step is trip distribution, which is to recombine the production and attraction trips. The most common model of trip distribution is the gravity model. The general function of the gravity model is [16]:

$$
\begin{gathered}
T_{i j}=a_{i} b_{j} P_{i} f\left(t_{i j}\right) \\
a_{i}=\left[\sum_{j} b_{j} A_{j} f\left(t_{i j}\right)\right]^{-1} \\
b_{j}=\left[\sum_{i} a_{i} P_{i} f\left(t_{i j}\right)\right]^{-1}
\end{gathered}
$$

Tij is the number of trips from Zone $i$ to Zone $j$ for each trip purpose, $f(t i j)$ is the impedance function or network level of the service function (characterized by travel time and generalized cost). $A j$ is the trip attraction of Zone $j$ and $P i$ is the trip production of Zone $i$. Parameter beta of the gravity model for this study was obtained from the calibration based on the observed OD matrix and trip impedance data.

Once the OD matrix is produced, the next stages are mode choice and route choice (or trip assignment). These two steps are generally calculated by the software used for the modeling, frequently according to disaggregate models. Indeed, since the $60 \mathrm{~s}$ and the first development of transportation models, methods and modeling software became increasingly efficient and powerful.

\section{Method}

The study area (Sarbagita metropolitan area) consists of 4 regencies, i.e., Denpasar, Badung, Gianyar and Tabanan. The study area was divided into 30 Traffic Analysis Zones (TAZ) in the model. Actually, the network is characterized by zones (TAZ) and macro zones. Macro zones are made of several zones (2 or 3 ) but are still smaller than the administrative regencies: of 12 macro zones, 2 are in Gianyar, 2 others in Tabanan, and the last 8 are equally distributed between Badung and Denpasar.

Once the areas and road types have been defined, it is possible to model the network. Figure 1 represents the Sarbagita, the traffic analyses zones, and the links (roads). The zones are colored according to their density. The software visum allows graphics changes only from "type attribute", zone types and link types. Therefore in the figure, the lightest zones are the least dense (types 6 to $9-1800$ to $300 \mathrm{p} / \mathrm{km}^{2}$ ) and the red areas are the densest (types 0 to $3-13000$ to $5000 \mathrm{p} / \mathrm{km}^{2}$ ). 


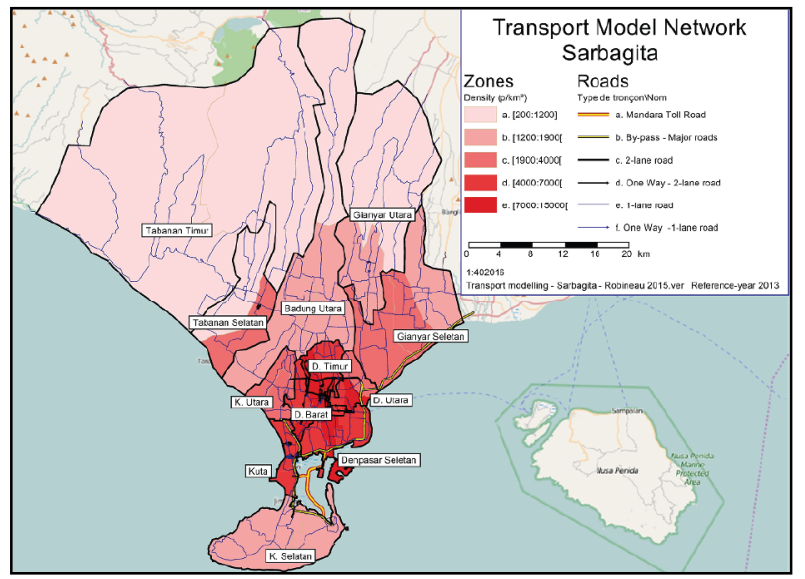

Fig. 1. Transport model network for Sarbagita Metropolitan Area

The origin-destination trip matrices were obtained from the Department of Transport [17]. Socio-economic data was obtained from the Bureau of Statistics of Bali Province [18]. The average daily traffic (ADT) was obtained from the Department of Public Works [19]. The four-steps models developed include trip generation model, trip distribution, mode split and trip assignment. Visum software was used for modelling purposes.

\section{Results and discussion}

\subsection{Travel pattern for sarbagita metropolitan area}

Figure 2 and 3 show respectively the trip assignment on the Sarbagita road network and the total trip emission for each traffic zone analysed.

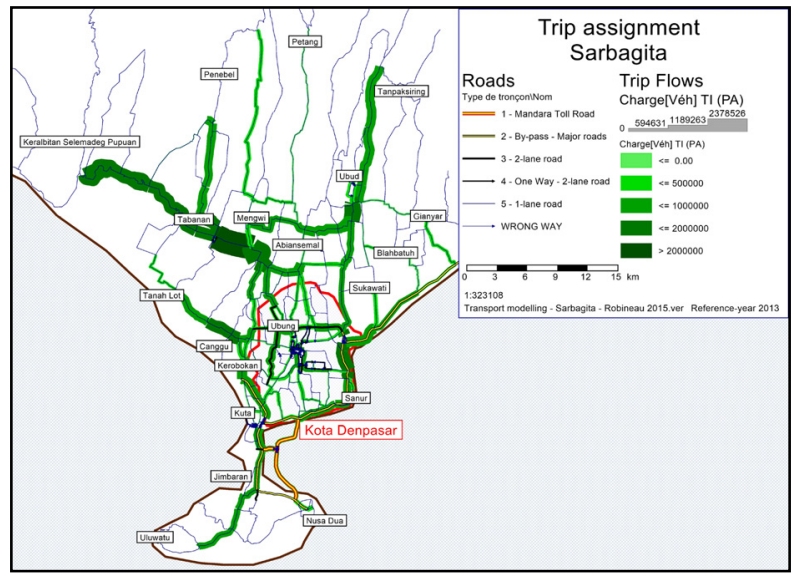

Fig. 2. Trip assignment

In the first figure, it can be seen which sections of the Sarbagita are the busiest per year. It is very clear that the Gilimanuk-Denpasar road is the most commonly used section. The trip flow on the section of this road between Tabanan and Mengwi supports an annual traffic of 4.5 million passengers (half for each way). 
Figure 3 shows the TAZ traffic emitted. The large areas of the northern Sarbagita, where the population density is very low, are still the most displacement-generating areas. It is impossible to determine what actually occured there since the mesh is too broad. It is therefore possible to emit a reservation on the Kabupaten Tabanan mesh which is perhaps not quite accurate. Therefore, the mesh of Kabupaten Tabanan is, perhaps, not precise enough.

The major tourist spots also generate important flows. Roads between these zones are the major inter-Sarbagita movement axes. The Kuta-Sanur-Ubud axis and the Nusa DuaJimbaran-Kuta-Canggu-Tanah Lot axis are particularly important. Finally, the centre of Denpasar, where administrative services are clustered, is also a quite important waypoint. Thus, the busiest roads are the Denpasar-Gilimanuk road, the Ngurah Rai Bypass, Sunset Road, Canggu road and the roads in Mengwi, Denpasar and Ubud. In the Jimbaran area, the Uluwatu I and Uluwatu II roads are busier than the part of the Ngurah Rai Bypass between Nusa Dua and Jimbaran. This might be one possible explanation for the difficulty of the Denpasar-Nusa Dua Trans Sarbagita bus corridor to attract passengers when the corridor to Jimbaran is always full.

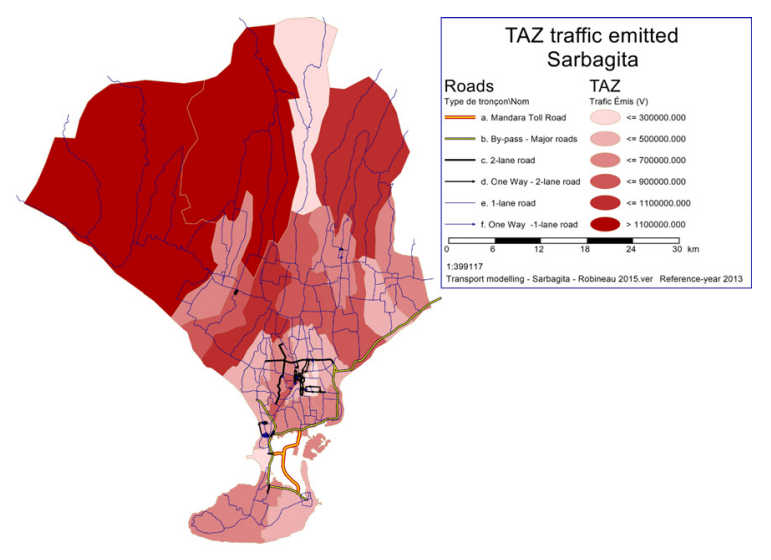

Fig. 3. Traffic emitted

In terms of numbers, the model establishes a figure of 17 million trips a year all over the Sarbagita. About 3.9 million trips from Tabanan (4 TAZ, 10\% internal traffic), 3.3 million from Gianyar (5 TAZ, 18\% internal traffic), 4.6 million from Badung (9 TAZ, 22\% internal traffic), and 5.7 million from Denpasar (12 TAZ, 40\% internal traffic) were estimated. The traffic inside of Denpasar city seems to be very low, but the percentage of internal traffic is not really significant.

Figure 4 shows a simplified form of the metropolitan general movement flows. This helps one understand the trip shape in the Sarbagita more easily. This presents a double loop with three ramifications to Uluwatu, Nusa Dua, and Gianyar. The first loop corresponds to the Ngurah Rai Bypass (including Sunset Road and Gatot Subroto road) around Denpasar. The second loop connects Kesiman (north-east of Denpasar city to Ubud, Tabanan-Mengwi and Canggu-Tanah Lot. 


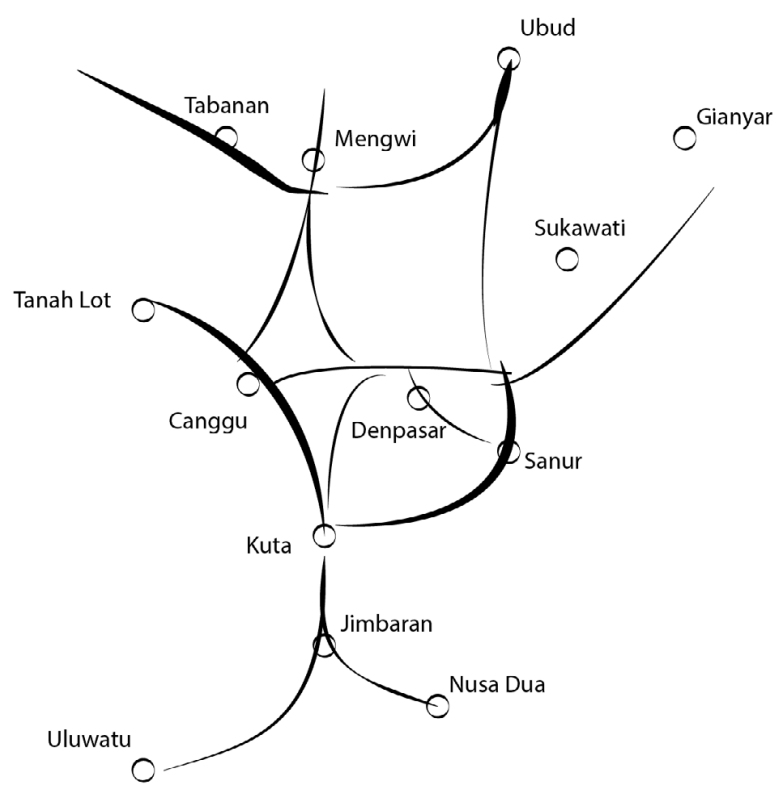

Fig. 4. Schematic trip representation

The model ultimately used only six reference values for the estimation of a 30 TAZ OD matrix that represents 870 values. At another level, a calibration parameter was applied between the TAZ of different regencies but not between the TAZ of the same regency. As was mentioned previously, the results recorded from inside of Denpasar seem to be distorted and very low. As trips inside of one zone were not represented, and each zone includes at least one or several villages, including within themselves some communities, one can easily understand the low values of the movement between the model traffic analyses zones.

Based on the modeling results, it can be seen that the development of the public transport (Trans Sarbagita) network must be made a priority, especially, on the axes highlighted in the modelling (the double loop). This is not only to relieve the Private Transport (PrT) network but also to respond to an obvious demand. However, the TAZ of the model are very large (dozens of square kilometers, hundreds for the biggest areas); at the same time, the pedestrian drawdown radius of a classic bus stop is around $300 \mathrm{~m}$ and reaches $500 \mathrm{~m}$ for the more "structuring" corridors. The drawdown of a metro station is usually between $500 \mathrm{~m}$ and $800 \mathrm{~m}$ (more with an ideal distribution of the entrances). Therefore, the stops of the Trans Sarbagita bus network must not be just simple bus stops: the Trans Sarbagita stops have to be real multimodal transit hubs. First, it should be designed to facilitate convenient public transport and private transport distribution. The secondary and touristic lines, micro bus lines, motorcycles (ojeks) and taxis must have easy stops; on the other side safe parking areas for cars and motorcycles must be considered.

\subsection{A strategy for the Sarbagita transport master plan}

The Sarbagita metropolitan area must implement a medium-long term public transportation development programme. This programme should not only foresee the development of the Trans Sarbagita bus network but must also consider the entire mobility chain in the metropolitan area. Each of the actors, including economic agents, must be incorporated in the model development. To initiate this movement, Figure 5 shows an outline of a proposed Transportation Development Plan for the Sarbagita area. The first step is to define and 
support the development of public transit (Phase 1) and consider the introduction of a traffic restraint policy at a later stage (Phase 2). Phase 1 is split into four sub-categories of equal prominence: a good picture for public transport with a multimodal transportation promotion, a clear classification of transport modes and a widespread use of information technology (IT). The launch of the second phase is conditioned to the success of Phase 1 and to political will. As indicated above, it would be socially unjust to limit people as to the use of their vehicles without any real available alternative. Determining the success of phase 1 requires consideration whether each of the four points in this phase are fulfilled.

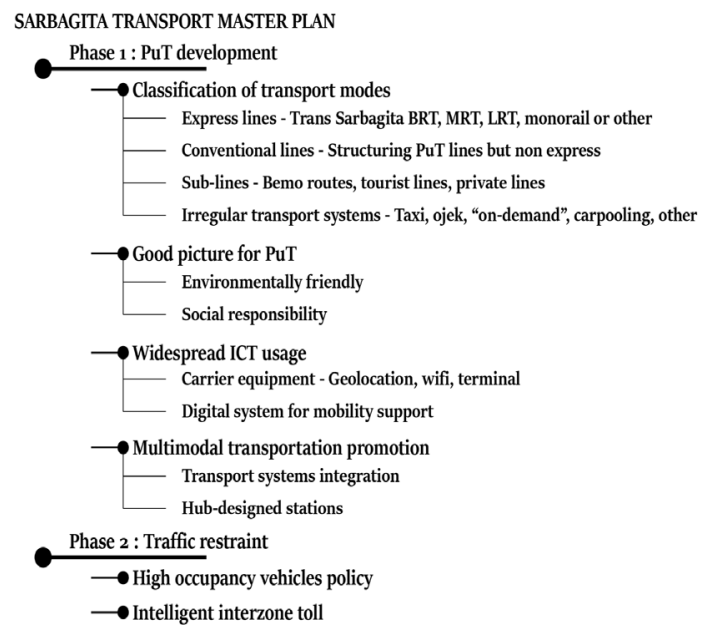

Fig. 5. Transportation development plan for Sarbagita Metropolitan Area

\subsection{Towards a strong ecological and social image of public transport}

A strong ecological image of public transport $(\mathrm{PuT})$ is very important for the user, maybe even more important than its actual environmental cost. Indeed, the picture of private transport (PrT) should be clean because although in comparison with PrT, a bus is better for the environment than dozens of motorcycles. The use of natural gas or electric buses needs to be promoted. A restriction policy needs to be applied on polluting private buses, for example by giving higher tax to the polluting vehicles and providing subsidy to promote clean vehicles.

In addition to the ecological dimension, the transport system must integrate a social dimension. It is not a question of satisfying the needs of certin sector but to satisfy the needs of the Balinese society and therefore the needs of the Balinese themselves. This is a social responsibility. For this, considerations should be given to set up appropriate lines for schoolchildren as well as preferential rates for them. Because behavioral change in societies occurs primarily through younger members, a major effort must be made to invite more young people to use public transport (ecology and urbanism workshops, mobility training, and advertising).

\subsection{Classification of transport modes}

The public interest transport network is divided into three capacity categories: the conventional network (large capacity), the irrigating lines (medium capacity), and the irregular transportation (low capacity). The term public interest transport is introduced here in order to make the differentiation between the conventional public transport (public or 
semi-public) and the various alternative transport systems (private). It should be noted that term "public transportation" is used to refer to all public interest modes (from BRT, taxi, micro bus (bemo) and motorcycles (ojek)). The conventional network is characterized by expressways and non-express routes connecting the main points of interest of the Sarbagita (Ubud, Tanah Lot, Kuta, Jimbaran, Sanur, Nusa Dua, Denpasar Centre, Mengwi, and any other location of which its importance was previously predetermined).

Ultimately, the goal is that all non-express routes become express routes. The means of transport for express routes are set from line characteristics (territorial, topographical, social, political will, finance and cost). In order to be qualified as an express line, a route must operate exclusively on own site (or almost exclusively); it may be a BRT, MRT, LRT, monorail or even cable car system or other as long as the level of service is sufficient (large capacity, high frequency, the range of operating hours is a least $15 \mathrm{~h}$ minimum between the first and last vehicle in service, minimum commercial speed $20 \mathrm{kph}$ ). The irrigating or local lines are all lines set up by the public or private sector covering flows to the conventional network. These may be public lines, paratransit lines such as bemo but also tourist lines or other means as long as the roads are predefined, regular and daily.

A time sheet is not necessarily needed (in the case of micro bus (bemo) lines), but the time amplitude and the minimum frequency must be set beforehand. The mobility of users must be the main preoccupation of any transportation network, and since private operators are often vectors of innovation, the introduction of a private line concurrent to the conventional network is not prohibited. However, smart taxation should be implemented on this type of concurrency. This taxation should not be discouraging because in this case the approval of competition would be useless, but this should help the public operator to compensate part of its losses.

The third category of transport which is included in the public utility transportation network is made of all means of transport that can be characterized as irregular transport modes. These are primarily taxis and motorcycle taxis (ojek), and also any other form of similar transport mode. Likewise, the demand responsive transit that experiences a strong development in rural areas of developed countries is included in this class. To this category, various modes of car-sharing and collaborative economy such as carpooling for example, must be added.

\subsection{Improvement and progressive use of ICT}

In order to contribute to the achievement of smart mobility, information communication technology (ICT) improvement is required, for example by improving smartphone application to support transportation performances. This is also done to promote the development of ICT on a large scale, and beyond the world of transportation (for example: as part of the tourism industry or the building sector). This must be supported by a strong political will to integrate ICT in the Balinese society.

\subsection{Multimodal transportation promotion}

Integration between different modes of transport is essential for reaching efficiency. This requires from the infrastructure point of view a competent design of the stops of the structuring lines that must be visualized as transportation hubs. Each bus stop of the Trans Sarbagita bus must be set up while taking into account its direct environment (within 500 $\mathrm{m}$ ). A stop of a BRT line should be more than a simple stop; it should be a real little station, a multimodal transit hub. The flow patterns for each mode (including walk and soft modes) must be considered around these hubs. From the point of view of the network, it is also about integrating the different modes between one another. An end-to-end service must be 
provided for passengers taking the express line to travel the last kilometers and reach their ultimate destination.

Ideally, each Balinese should have the ability, at any point from the Sarbagita, to reach the express lines from a single means of transport. Thus, for any path, a maximum of three different transport categories should be used (changes within the conventional network can still obtrude). Finally, every telepayment must be part of the Trans Sarbagita bus online payment system. If a company wants to create a computerized payment offer or implement a ticketing system, it must absolutely do so in accordance with the payment system of the Trans Sarbagita bus.

\subsection{Traffic restraint policy}

If all of the points developed in phase 1 are deemed to have been achieved, phase 2 may optionally be implemented. The idea would be to combine a policy of taxation with the promotion of a sharing and caring ideology. Initially, conventional taxation is implemented on the purchasing and use of private vehicles (at least in terms of pollution and, maybe, in order to reduce private transport possession if the situation in the Sarbagita itself deteriorates). Then, an intelligent interzone toll system may be implemented. The principle of this interzonal toll system is to tax the trips on the metropolitan scale. Indeed, if phase 1 is reached, this kind of trip shall be easily completed by public transport. Nevertheless, the implementation of a toll between two areas means that if someone is living in a border between two zones, he should also pay for a short trip, which is counterproductive. Thus, the idea is to set up a grid of Sarbagita and charge a trip between two non-adjacent areas. The further the trip, the more the driver is likely to be taxed.

The implementation of coercive policies on the use of private transport, such as in Singapore, is extremely efficient in order to increase the use of public transport. However, transport policies must be implemented in favor of the citizens, including helping poor citizens reach new opportunities.

\section{Conclusions}

This study has highlighted key issues for the Sarbagita transport systems. It was found that inter-regencies trips are just as numerous as internal regency trips. The traffic volumes on the majority of the main road network were predicted to exceed the road capacity in the near future. This chaotic traffic in appearance certainly affects the image that international tourists have made of Bali. The strategies proposed were to strengthen public transport system as the backbone of the transport system in the Sarbagita area. Implementation of a good public transport system needs to be supported by a strong policy to restrict the ownership and use of private motor vehicles. It has been observed that transit in the Sarbagita metropolitan area is predominantly done between the main touristic points, which are also strong employment areas. The development of mass public transport system must be made a priority on these axes (the double loop). It has also been found in a second modeling of Denpasar City that a strong travel demand inside of the city must be taken into account. Finally, an issue that has not been investigated in this study but nevertheless deserves special consideration is the issue of financing of infrastructure and urban networks. 


\section{References}

1. United Nations, Department of Economic and Social Affairs, World Urbanization Prospects: The 2014 Revision, Highlights (ST/ESA/SER.A/352) (2014)

2. OECD, Managing Urban Traffic Congestion, Organisation for Economic Development, Paris, (2007)

3. J.L. Bowman, M.E. Ben-Akiva, Activity-based disaggregate travel demand model system with activity schedules. Transp. Res. A 35, 1-28 (2001)

4. J.A. Carrasco, E.J. Miller, Exploring the propensity to perform social activities: a social network approach. Transportation 33(5), 463-480 (2006)

5. H.J. Timmermans, J. Zhang, Modeling household activity travel behavior: examples of state of the art modeling approaches and research agenda. Transp. Res. B 43(2), 187190 (2009)

6. K. Manaugh, A.M. El-Geneidy, What makes travel 'local': Defining and understanding local travel behavior. The Journal of Transport and Land Use, 5 (3), pp. 15-27, doi: 10.5198/jtlu.v5i3.300 (2012)

7. D. Salon, E.M. Aligula, Urban travel in Nairobi, Kenya: analysis, insights, and opportunities. Journal of Transport Geography, 22, pp. 65-76 (2012)

8. M. Saberi, H.S. Mahmassani, D. Brockmann, A. Hosseini, A complex network perspective for characterizing urban travel demand patterns: graph theoretical analysis of large-scale origin-destination demand networks. Transportation. Springer Science and Business Media. New York. DOI 10.1007/s11116-016-9706-6 (2016)

9. Y. Chen, A. Frei, H.S. Mahmassani, Exploring activity and destination choice behavior in social networking data. Proceedings of the transportation research board 94th annual meeting (No. 15-5808), Washington (2015)

10. C. Daganzo, Urban gridlock: macroscopic modeling and mitigation approaches. Transp. Res. B 41(1), 49-62 (2007)

11. N. Geroliminis, C. Daganzo, Existence of urban-scale macroscopic fundamental diagrams: some experimental findings. Transp. Res. B 45(3), 605-617 (2008)

12. H. Mahmassani, M. Saberi, A. Zockaie, Urban network gridlock: theory, characteristics, and dynamics. Trans. Res. C 36, 480-497 (2013)

13. M. Saberi, H. Mahmassani, T. Hou, A. Zockaie, Estimating network fundamental diagram using threedimensional vehicle trajectories: extending Edie's definitions of traffic flow variables to networks. Transp. Res. Rec. 2422, 12-20 (2014)

14. J.W. Joubert, K. Axhausen, A complex network approach to understand commercial vehicle movement. Transportation 40(3), 729-750 (2013)

15. J. Kim, H.S. Mahmassani, Spatial and temporal characterization of travel patterns in a traffic network using vehicle trajectories. Trans. Res. C 59, 375-390 (2015)

16. M.G. McNally, The Four Step Model, to appear as Chapter 3 in Hensher and Button (eds). "Handbook of Transport Modelling", Pergamonn 2nd Ed (2007).

17. Department of Transport, Republic of Indonesia, Origin-Destination Matrix of Bali Province. Jakarta (2016)

18. Bureau of Statistic of Bali Province, Bali in Figure 2015, Denpasar, Bali (2016)

19. Department of Public Work, The average daily traffic (ADT) of national road in Bali Province. Jakarta (2016) 